\title{
Successful Treatment of Vancomycin-Resistant Enterococcus Ventriculitis in a Child
}

\author{
Paulo Sérgio Lucas da Silva, Henrique Monteiro Neto and Lílian Márcia Sejas \\ Pediatric Intensive Care Unit, Department of Pediatrics, State Hospital of Diadema, Federal University of São Paulo; São Paulo, SP, Brazil
}

\begin{abstract}
Enterococci are an uncommon cause of CNS infection. A 20 month-old boy, diagnosed with hydrocephalus with ventriculoperitoneal shunt and history of lengthy hospitalization and use of wide spectrum antibiotics, was admitted to the pediatric intensive care unit diagnosed with ventriculitis. On the $14^{\text {th }}$ day of empirical antibiotic therapy (vancomycin and meropenem) the child presented fever while the CSF sample culture evidenced vancomycinresistant Enterococcus faecium. The patient received intravenous linezolid achieving cerebrospinal fluid sterilization. Conclusion: Intravenous linezolid appears to be a safe and effective therapy for vancomycin-resistant enterococcus ventriculoperitoneal shunt infection.
\end{abstract}

Key-Words: Vancomycin, resistance, treatment.

Enterococci are known for causing urinary tract infection, infections of surgical wounds, nosocomial bacteremia, infectious endocarditis and, rarely, central nervous system infections [1]. Over the past decade, enterococcus has become a significant nosocomial pathogen, particularly given their resistance to multiple antimicrobial agents, and thus represents a challenge due to the limited therapeutic options available [2].

Only a few studies [3-9] have reported the use of linezolid in the treatment of central nervous system infection by vancomycin-resistant enterococcus (VRE), and only one case reported a pediatric patient [4]. The present study described treatment of ventriculitis caused by vancomycin-resistant enterococcus in an infant with multiple comorbidities.

\section{Case Report}

A 20 month-old boy, with underlying diagnosis of neurodevelopmental delay and hydrocephalus with ventriculoperitoneal shunt (VPS) secondary to Pneumococcus meningitis at 6 months of life, presented a cardiorespiratory arrest on his arrival in hospital, and was then resuscitated over 23 minutes. The infant remained hospitalized for 10 days within the pediatric intensive care unit (PICU), diagnosed with aspirative pneumonia and cardiogenic shock, receiving oxacillin and ceftriaxone.

On the $18^{\text {th }}$ day, the patient was readmitted to the PICU with a diagnosis of septic shock due to central venous catheter-related infection, being discharged from the PICU on the $7^{\text {th }}$ day, having received vancomycin and cefepime for a total of 3 weeks. On the $39^{\text {th }}$ day he was readmitted to the PICU diagnosed with ventriculitis. The cerebrospinal fluid (CSF) sample obtained by reservoir puncture revealed $71 \mathrm{cells} / \mathrm{mm}^{3}$ (72\% neutrophils; glucose $13 \mathrm{mg} / \mathrm{dL}$ and protein $69 \mathrm{mg} / \mathrm{dL}$ ). Cultures were negative. The patient received external ventricular drain associated with vancomycin and meropenem

Received on 18 October 2006; revised 9 March 2007.

Address for correspondence: Dr. Paulo Sérgio Lucas da Silva. Rua Aroeiras 30 apt. 22, Santo Andre, São Paulo, Brazil. Zip code: 09090-000. Phone/Fax number: +55 11 32889928. E-mail: psls.nat@terra.com.br.

The Brazilian Journal of Infectious Diseases 2007;11(2):297-299. (c) 2007 by The Brazilian Journal of Infectious Diseases and Contexto Publishing. All rights reserved. empirically for 4 weeks, undergoing a VPS on the $30^{\text {th }}$ PICU day. On the $14^{\text {th }}$ postoperative (PO) day, the patient developed perivalvular abscess, the CSF obtained from the shunt reservoir presented 74 cells $/ \mathrm{mm}^{3}$ (79\% neutrophils), upon which the patient was submitted to external ventricular shunt (EVS) whilst vancomycin and meropenem were resumed. On the $6^{\text {th }}$ PO day after EVS, fluconazole was associated due to the presence of yeast in a routine CSF sample. Cultures for fungus were negative. On the $14^{\text {th }}$ day of antibiotic therapy, the patient evolved with fever $\left(39^{\circ} \mathrm{C}\right)$, presenting the following laboratorial exams: white blood cells (WBC) $23,000 / \mathrm{mm}^{3}$, platelets $156,000 / \mathrm{mm}^{3}$, C-reactive protein $20 \mathrm{mg} / \mathrm{dL}$, CSF with 15 cells ( $90 \%$ neutrophils), glucose $45 \mathrm{~g} / \mathrm{dL}$, protein $910 \mathrm{~g} / \mathrm{dL}$, Gram stain showed Gram-positive cocci in chains, and 2 serial CSF cultures yielded Enterococcus faecium resistant to vancomycin, ampicillin, streptomycin, ciprofloxacin, chloramphenicol and susceptible to gentamicin. The vancomycin minimum inhibitory concentration (MIC) of this isolate was $>32 \mu \mathrm{g} / \mathrm{mL}$ (using an E-test method with an inoculum density of $0.5 \mathrm{McF}$ arland standard). Based on this information, he was switched to linezolid monotherapy, dosed at $10 \mathrm{mg} / \mathrm{kg}$ intravenously every 8 hours.

Following the $2^{\text {nd }}$ day of linezolid, the patient became afebrile, and after the $3^{\text {rd }}$ day had sterile CSF. Following 4week treatment with linezolid, the patient had a new VPS in place (CSF: 1 cell $/ \mathrm{mm}^{3}$, glucose $54 \mathrm{~g} / \mathrm{dL}$ and protein $90 \mathrm{~g} / \mathrm{dL}$ ) and C-reactive protein of $1.78 \mathrm{mg} / \mathrm{dL}$. Treatment continued for a further 2 weeks, during which time CSF samples remained sterile. Concentrations of linezolid in CSF were not recorded. The patient tolerated the 6-week treatment without showing evidence of bone marrow suppression. Fecal cultures obtained during treatment with linezolid were negative. The patient evolved requiring ventilation assistance due to neurologic compromise, and was cared for in an intermediate care unit.

\section{Discussion}

The emergence of nosocomially acquired vancomycinresistant enterococci has become a significant concern and a treatment challenge to physicians [3]. Approximately $12 \%$ to $18 \%$ of enterococci in the United States exhibit vancomycin resistance [3]. 
Risk factors for vancomycin-resistant enterococcus (VRE) colonization in children include young age, use of invasive devices, antimicrobial drug administration, immunosuppression, low birth weight, and underlying malignancy [10]. Such patients have commonly been treated with vancomycin or broadspectrum antibiotics before VRE isolation [11]. Two important factors predisposing patients to VRE infection are the percentage of hospital days receiving antimicrobial therapy of any type and the number of days receiving intravenous vancomycin [7]. Our patient had received several weeks of broadspectrum antibiotics before developing VRE meningitis; this prolonged use of antibiotics, associated with the long stay in hospital were likely contributory factors in both colonization and subsequent infection with VRE. However, treatment with lengthy courses of broad-spectrum antibiotics is often unavoidable in critically ill patients.

The National Nosocomial Infections Surveillance system of the Centers for Disease Control and Prevention reported vancomycin resistance in $28.5 \%$ of nosocomial enterococcal intensive care unit infections in 2003 [12]. In a recent study, $14 \%$ of VRE-colonized patients progressed to infection within 15 days of a positive surveillance culture [13]. A recent review noted that, although Enterococcus faecalis is responsible for $80 \%$ of enterococcal infections, E. faecium strains account for $98 \%$ of vancomycin-resistant cases [14].

There are no established guidelines for the treatment of central nervous system infection caused by VRE. Therapeutic options for vancomycin-resistant enterococci are limited because these organisms are usually resistant to multiple antimicrobial agents. Treatment often has to include investigational drugs or less tested new drugs. In our patient the therapy included intravenous linezolid. To the best of our knowledge, there has only been 1 previous case report of ventriculitis due to enterococcus in a child treated successfully with linezolid [4].

Linezolid, the first member of the oxazolidinones class of antibiotics licensed by the U.S. Food and Drug Administration (FDA), inhibits bacterial protein synthesis by binding to the $50 \mathrm{~S}$ ribosomal subunit. It is approved for use in adults and children for serious infections caused by Enterococcus faecium or Enterococcus faecalis including vancomycin-resistant strains (VRE), Staphylococcus aureus including methicilllin-resistant strains (MRSA), coagulatenegative staphylococci and streptococci including penicillinresistant Streptococcus pneumoniae [15]. Linezolid is essentially bacteriostatic. In vitro time-kill experiments against multidrug-resistant (including vancomycin-resistant) enterococci, linezolid was not bactericidal but had greater bacteriostatic activity against these organisms [16].

CSF penetration of linezolid suggests utility in treatment of meningitis and intracranial prosthetic device infections. In individuals with noninflamed meninges, linezolid concentrations in CSF were $70 \%$ of plasma concentrations [17]. In adults, reversible thrombocytopenia is the major hematologic consequence of linezolid use, generally occurring after $\geq 2$ weeks of treatment and thought to be due to transient bone marrow suppression. In children, thrombocytopenia is less common; however, a complete blood count should be monitored weekly while children are receiving linezolid [17]. In adults, linezolid-induced neuropathy has been reported among patients receiving the drug for $>6$ months.

Vancomycin and aminoglycosides with variable penetration of the blood-brain barrier and monitoring CSF levels is recommended. Intraventricular administration of antimicrobials with irregular penetration of blood-brain barrier makes theoretical sense but is controversial [18]. Problems with intraventricular antibiotics include allergic reactions, drug-induced inflammation and toxic or inadequate concentrations [18]. Even though our case presented gentamycin-susceptible enterococcus, the patient was successfully treated without needing intraventricular administration of drugs.

Optimal management of ventricular shunt infection requires removal of the shunt, placement of a temporary external ventricular drain (EVD), followed by reinternalization after CSF sterilization. A recent analysis strongly confirmed this as the most effective treatment method [19].

Length of time on antibiotic therapy in patients with ventriculoperitoneal shunt infection remains controversial. Studies employing linezolid for the treatment of VPS infections range from 3 to 12 weeks in length $[4,8,20,21]$. Despite receiving prolonged treatment, our patient presented no bone marrow compromise according to serial hemograms. However, peripheral neuropathic signs could not be assessed in this case because the patient presented severe neurologic compromise due to the underlying disease and comorbidity. In conclusion, intravenous linezolid appears to be a safe and effective therapy for vancomycin-resistant enterococcus ventriculitis. Our success with linezolid in this instance is encouraging for the future role of this class of drugs for the treatment of shunt infections.

\section{References}

1. Stevenson K.B., Murray E.W., Sarubbi F.A. Enterococcal meningitis: report of four cases and review. Clin Infect Dis 1994; $18: 233-9$.

2. Rice L.B. Emergence of vancomycin-resistant enterococci. Emerg Infect Dis 2001;7:183-7.

3. Kanchanapoom T, Koirala J, Goodrich J, Agamah E, Khardori N. Treatment of central nervous system infection by vancomycinresistant enterococcus faecium. Diagn Microbiol Infect Dis 2003;45:213-5.

4. Graham P.L., Ampofo K., Saiman L. Linezolid treatment of vancomycin-resistant Enterococcus faecium ventriculitis. Pediatr Infect Dis J 2002;21:798-800.

5. Baysallar M., Izci Y., Kilic A., et al. A case of ventricular drainage infection with a rare pathogen in cerebrospinal fluid: vancomycin-resistant Enterococcus faecium. Microb Drug Resist 2006; $12: 59-62$.

6. Zeana C., Kubin C.J., Della-Latta P., Hammer S.M. Vancomycinresistant Enterococcus faecium meningitis successfully managed with linezolid: case report and review of the literature. Clin Infect Dis 2001;33:477-82. 
7. Steinmetz M.P., Vogelbaum M.A., De Georgia M.A., et al. Successful treatment of vancomycin-resistant enterococcus meningitis with linezolid: case report and review of the literature. Crit Care Med 2001;29:2383-5.

8. Hachem R., Afif C., Gokaslan Z., Raad I. Successful treatment of vancomycin-resistant Enterococcus meningitis with linezolid. Eur J Clin Microbiol Infect Dis 2001;20:432-4.

9. Shaikh Z.H., Peloquin C.A., Ericsson C.D. Successful treatment of vancomycin-resistant Enterococcus faecium meningitis with linezolid: case report and literature review. Scand J Infect Dis 2001;33:375-9.

10. Singh-Naz N., Sleemi A., Pikis A., et al. Vancomycin-resistant Enterococcus faecium colonization in children. J Clin Microbiol 1999;37:413-6.

11. Rubin L.G., Tucci V., Cercenado E., et al. Vancomycin-resistant Enterococcus faecium in hospitalized children. Infect Control Hosp Epidemiol 1992;13:700-5.

12. National Nosocomial Infections Surveillance (NNIS) System Report, data summary from January 1992 through June 2004, issued October 2004. Am J Infect Control 2004;32:470-85.

13. Calfee D.P., Giannetta E.T., Durbin L.J., et al. Control of endemic vancomycin-resistant Enterococcus among inpatients at a university hospital. Clin Infect Dis 2003;37:326-32.
14. Bratcher D.F. Vancomycin-resistant enterococci in the pediatric patient. Pediatr Infect Dis J 2001;20:621-2.

15. Tan T.Q. Update on the use of linezolid: a pediatric perspective. Pediatr Infect Dis J 2004;23:955-6.

16. Bostic G.D., Perri M.B., Thal L.A., Zervos M.J. Comparative in vitro and bactericidal activity of oxazolidinone antibiotics against multidrug-resistant enterococci. Diagn Microbiol Infect Dis 1998;30:109-12.

17. Saiman L., Goldfarb J., Kaplan S.A., et al. Safety and tolerability of linezolid in children. Pediatr Infect Dis J 2003;22:S193-200.

18. Anderson E.J., Yogev R. A rational approach to the management of ventricular shunt infections. Pediatr Infect Dis J 2005;24:557-8.

19. Schreffler R.T., Schreffler A.J., Wittler R.R. Treatment of cerebrospinal fluid shunt infections: a decision analysis. Pediatr Infect Dis J 2002;21:632-6.

20. Castro P., Soriano A., Escrich C., et al. J. Linezolid treatment of ventriculoperitoneal shunt infection without implant removal. Eur J Clin Microbiol Infect Dis 2005;24:603-6.

21. Gill C.J., Murphy M.A., Hamer D.H. Treatment of Staphylococcus epidermidis ventriculo-peritoneal shunt infection with linezolid. J Infect 2002;45:129-32. 